\title{
LAN Tool: A GIS Tool for the Improvement of Digital Elevation Models Using Drainage Network Attributes
}

\author{
Alexandra Gemitzi ${ }^{1 *}$, Odysseas Christou ${ }^{2}$ \\ ${ }^{1}$ Department of Environmental Engineering, Faculty of Engineering, Democritus University of Thrace, Xanthi, Greece \\ ${ }^{2}$ Geoinfo Cyprus Limited, Larnaca, Cyprus \\ Email: *agkemitz@env.duth.gr, geoinfo@geoinfo.gr
}

Received March 24, 2013; revised April 24, 2013; accepted May 24, 2013

Copyright (C) 2013 Alexandra Gemitzi, Odysseas Christou. This is an open access article distributed under the Creative Commons Attribution License, which permits unrestricted use, distribution, and reproduction in any medium, provided the original work is properly cited.

\begin{abstract}
Digital Elevation Models (DEMs) are constructed using altitude point data and various interpolation techniques. The quality and accuracy of DEMs depend on data point density and the interpolation technique used. Usually however, altitude point data especially in plain areas do not provide realistic DEMs, mainly due to errors produced as a result of the interpolation technique, resulting in imprecise topographic representation of the landscape. Such inconsistencies, which are mainly in the form of surface depressions, are especially crucial when DEMs are used as input to hydrologic modeling for impact studies, as they have a negative impact on the model's performance. This study presents a Geographical Information System (GIS) tool, named LAN (Line Attribute Network), for the improvement of DEM construction techniques and their spatial accuracy, using drainage network attributes. The developed tool does not alter the interpolation technique, but provides higher point density in areas where most DEM problems occur, such as lowland areas or places where artificial topographic features exist. Application of the LAN tool in two test sites showed that it provides considerable DEM improvement.
\end{abstract}

Keywords: Digital Elevation Model (DEM); Geographical Information Systems (GIS); Drainage Network; Spatial Interpolation; Hydrologic Modeling

\section{Introduction}

Digital Elevation Models (DEMs) are numerical representations of areas on the earth's surface produced applying interpolation techniques on altitude point data. DEMs provide vital input to several scientific areas and have numerous applications, among others in telecommunications, military services, location based services and environmental services. One of the most important applications of DEMs is their use in hydrologic modeling. As climate and land use changes have already brought serious impacts on local communities such as floods, droughts, soil erosion and pollution from point and non-point sources, scientists and decision makers are concerned on having realistic hydrologic models capable of simulating runoff, and sediment and nutrient loadings, in order to determine areas and ecosystems that are prone to be affected in the future.

The importance of DEM quality on hydrologic studies is already depicted by many researchers. Legleiter and

*Corresponding author.
Kyriakidis [1], indicated the problems usually encountered while constructing a DEM from a number of discrete altitude data points acquired through field survey and pointed out the fact that sophisticated methods of spatial prediction are no substitute for field data. The impact of DEM quality in hydrologic modeling, hazard modeling, stream network delineation, floodplain boundaries is highlighted in many studies [2-6].

Much research is also focused on detecting and improving the accuracy of DEMs and comparative studies have been conducted on the accuracy of the results of various interpolation techniques [7-12]. Several techniques have been developed for error minimization and DEM improvement including data fusion and other sophisticated techniques which however require the availability of multi-source DEM products [13,14]. Other methods provide combination or adjustments of various interpolation models $[15,16]$.

Early studies have dealt with the problem of improving DEM quality using drainage enforcement algorithms incorporating stream line data. Chen et al. [17], presented 
a comparative study of the drainage constrained methods, categorizing them in three main groups, i.e.: stream burning, surface fitting, and constrained-TIN algorithms. The stream burning algorithms apply a raster representation of a vector stream network in order to capture known hydrological features into a DEM $[18,19]$. The most popular surface fitting algorithm was presented by Hutchinson [20], known as ANUDEM algorithm, intending to remove pits from DEMs. In this methodology, irregularly spaced elevation data points, streamline and contour line data are used together with a finite difference interpolation technique. In the constrained TIN approaches, TINs are used instead of square grid cells in the DEM. Recently, Zhou and Chen [21], presented the compound method, constructing a drainage-constrained TIN, optimized to keep the important terrain features and slope morphology. Such algorithms are mainly targeting at DEM generalization, acting as correctors to the already constructed DEM, by altering point altitude where necessary and utilizing a specific interpolation method each time. In that way, although all previously mentioned methods provided DEM improvements, they achieved it through reconfigurations of certain interpolation methods and therefore they focused on a specific interpolation method. However none of the known interpolation methods provide accurate predictions in all cases and the development of a DEM improvement methodology using a certain interpolation technique is quite restrictive. This paper presents a DEM improving methodology that works before any interpolation is attempted and aims at improving input data point density incorporating stream line data into the original altitude point data set without altering any of the existing data points. This is achieved by assigning automatically an altitude attribute to the river network points, based on the intersections of the river lines with the altitude contours and by interpolating additional altitude points between intersection points. In that way, errors in the drainage network which are common due to artificial or even natural changes in topography, artificial drainage network construction, low density of point altitude data in lowland areas, or even errors produced by the interpolation may well be eliminated. The major difference from the previously mentioned methods for DEM improvement is that the present tool does not alter any of the initially existing data points. As it acts prior to DEM construction, it is not dedicated to any interpolation method and therefore it provides greater flexibility for the user to choose any interpolation method fits better to the case study each time.

Legleiter and Kyriakidis [1], mentioned that root meansquare error of the predictions provided by interpolation methods is directly proportional to the spacing between surveyed cross-sections, even in a reconfigured channel with a relatively simple morphology. In this context and because of the fact that the methodology presented herein provides higher density of point altitude data in the drainage network, it seems that it is a useful alternative for DEM improvement especially in cases where hydrologic modeling is of prime interest.

The methodology is demonstrated in two parts of the Vosvozis river basin, in northern Greece (Figure 1).

\section{Materials and Methods}

\subsection{Study Area}

The study area, Vosvozis river basin, located in northern Greece covers $357 \mathrm{~km}^{2}$ (Figure 1). The southern lowland part is an agricultural area. The river course in that part has undergone many interventions, thus changing completely the natural drainage pattern during the last decades. Moreover, many artificial drainage tiles have been constructed. The northern mountainous part is a forested area that has remained largely unchanged.

\subsection{Methodology and Theoretical Background}

LAN tool was developed using the Mapinfo MapBasic programming language and works as a seamless add on tool within Mapinfo Professional ver. 7 or later. The idea is to provide a higher point density as predefined by the user. In our case linear objects represent the drainage network of an area. Nevertheless, the same methodology

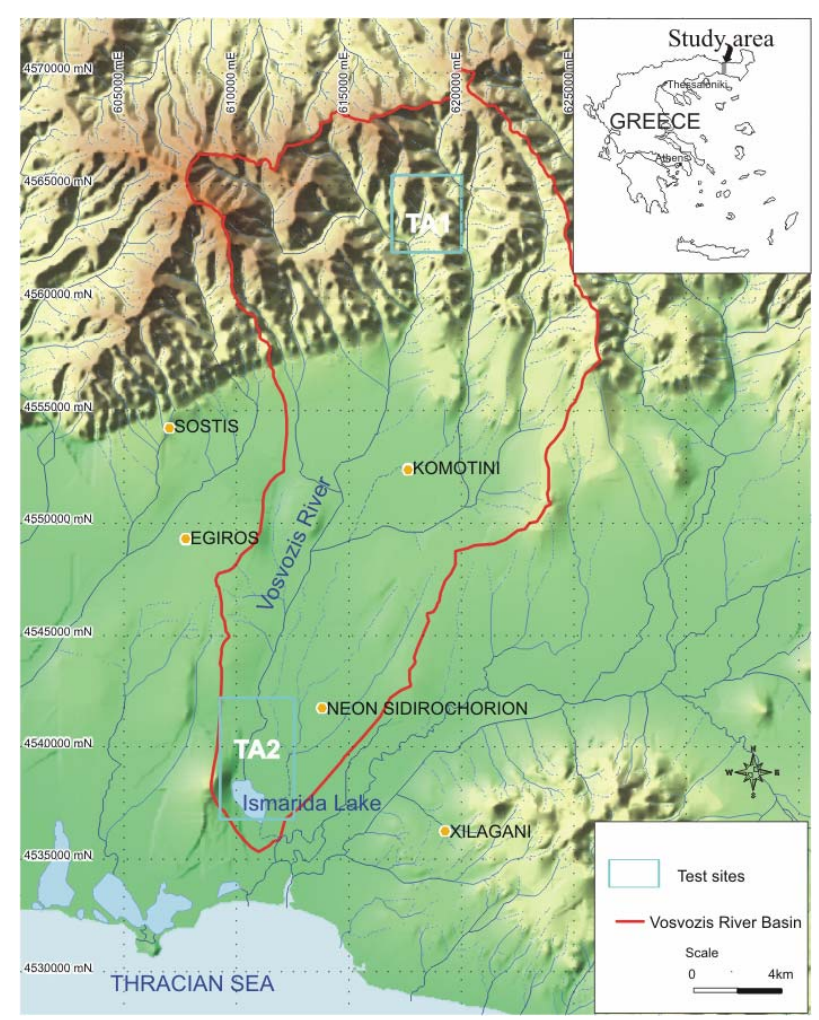

Figure 1. Location map of the study area. 
may well be applied for other linear features, e.g. for the road network of an area, where enhanced point density is required.

In any case the user is prompted to provide two vector files, one with the altitude contours that will be used for the construction of the DEM and one with the linear objects that will be used for the production of new altitude data points (Figure 2).

Subsequently, the user chooses the required point distance to be produced on the linear objects (Figure 3 ).

Then LAN tool detects all intersecting points of the given linear objects with the altitude contours as shown in Figure $\mathbf{4}$ and creates nodes at those points. In order to detect those intersections the well known sweep line algorithm is used [22]. This algorithm uses a sweeping vertical line from left to right in order to detect the $\mathrm{k}$ intersections of $\mathrm{n}$ line segments. The status of this sweep line changes constantly as the line moves and is defined by the set of segments intersecting it each time. The sweep line changes its status every time it passes an end point of a line segment or an intersecting point. As all data points are processed in sorted order the intersections are also provided in sorted order too. The advantage of this algorithm is that unlike conventional intersection search algorithms that require $\mathrm{O}\left(\mathrm{n}^{2}\right)$ time, the sweep line algorithm requires $\mathrm{O}((\mathrm{n}+\mathrm{k}) \log n)$ time to run and therefore it provides a fast and robust way to define intersection points.
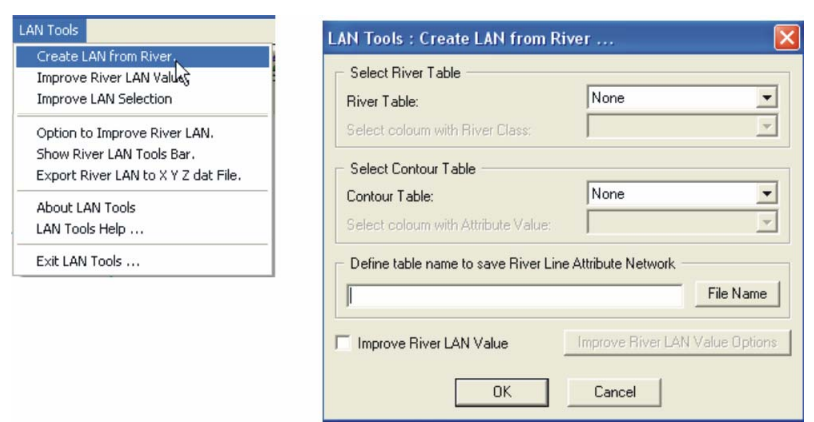

Figure 2. Selection of input files within LAN tool.
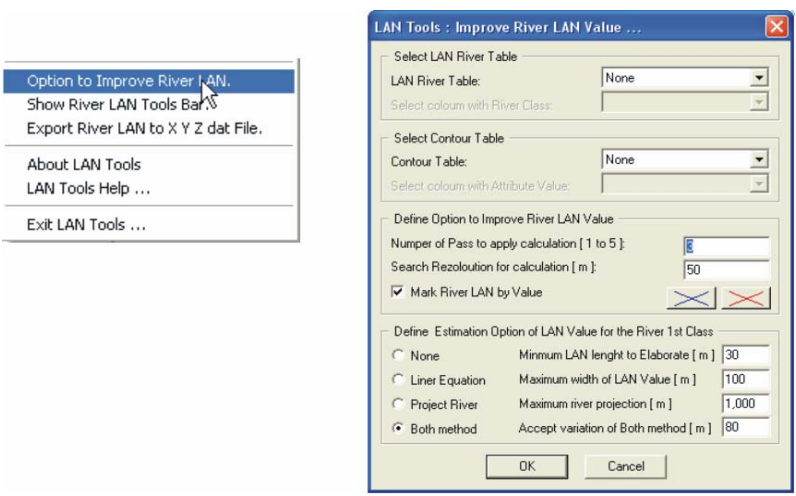

Figure 3. Selection of input parameters for LAN tool.

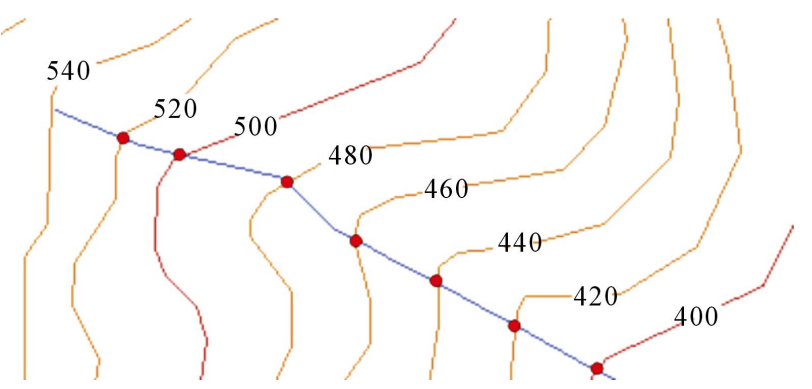

Figure 4. Intersection of altitude contour lines with river network.

Altitude values are assigned to those intersecting nodes based on the intersecting contour. Following, each line segment between those newly produced nodes is divided into equally spaced parts, and a new node is created for each one, according to the user predefined maximum required node distance. Then, LAN tool assigns altitude values to those new nodes performing either linear or cubic spline interpolation as shown on Figure 5, based on user's choice.

Linear interpolation fits a different linear function between each pair of existing data points, i.e., nodes of known altitude and returns the value of the relevant function at the interpolated points. The cubic spline fits a different cubic function between each pair of existing data points. Figure 5 shows an example of the application of those two different techniques. The produced nodes are spaced at $5 \mathrm{~m}$. It is true that the cubic spline produces a more realistic representation of the topography; however when the distance between original nodes is small (second and third point on Figure 4) then the two methods produce almost identical results. Taking into account the fact that linear interpolation is much faster, it depends on the user to choose the optimum method, based on the density of the original data points. After the new nodes have been assigned altitude values, LAN tool creates a new vector file containing all original and newly produced data points, in order to be used for DEM construction using conventional interpolation techniques.

It should be noted herein that also in the case of lowland areas where pits are often a problem when applying a hydrologic model, LAN tool is a useful alternative to pit removal algorithms used in most commercial GIS software, after DEM construction.

The flow chart of the developed software is shown on Figure 6.

In order to create the DEM for the study area, conventional topographic maps of various scales were digitized. The northern mountainous part was digitized from conventional maps of the Hellenic Military Geographical Service of scale 1:25,000 whereas for the southern plain topographic maps of scale 1:5000 were used in order to acquire higher density altitude point data in that part of 


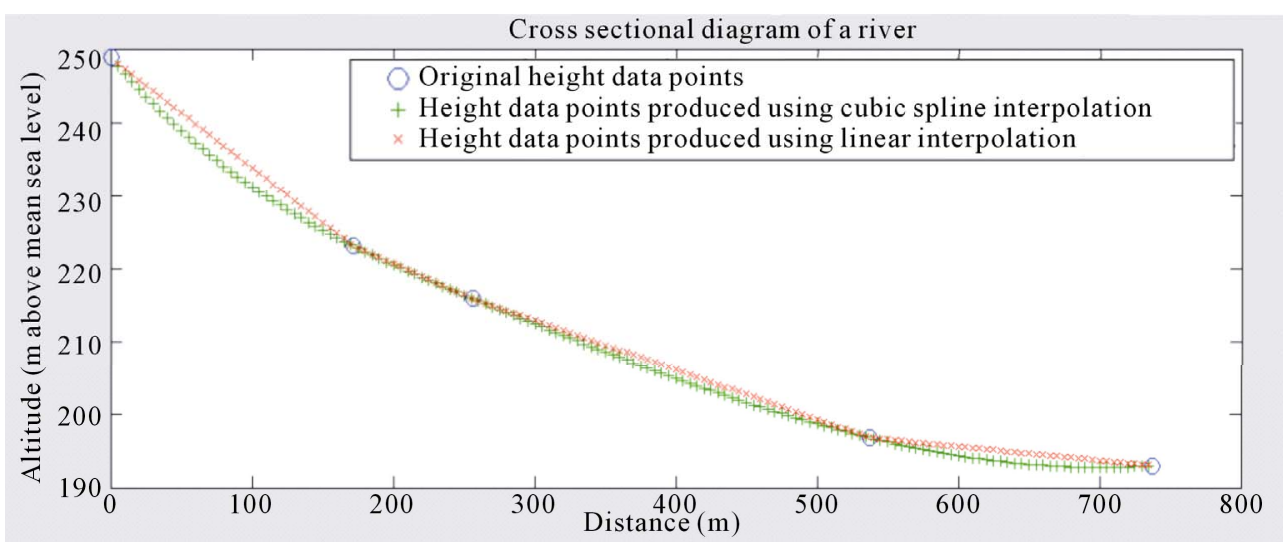

Figure 5. Cross sectional diagram of a river showing the results of linear and cubic spline interpolation.

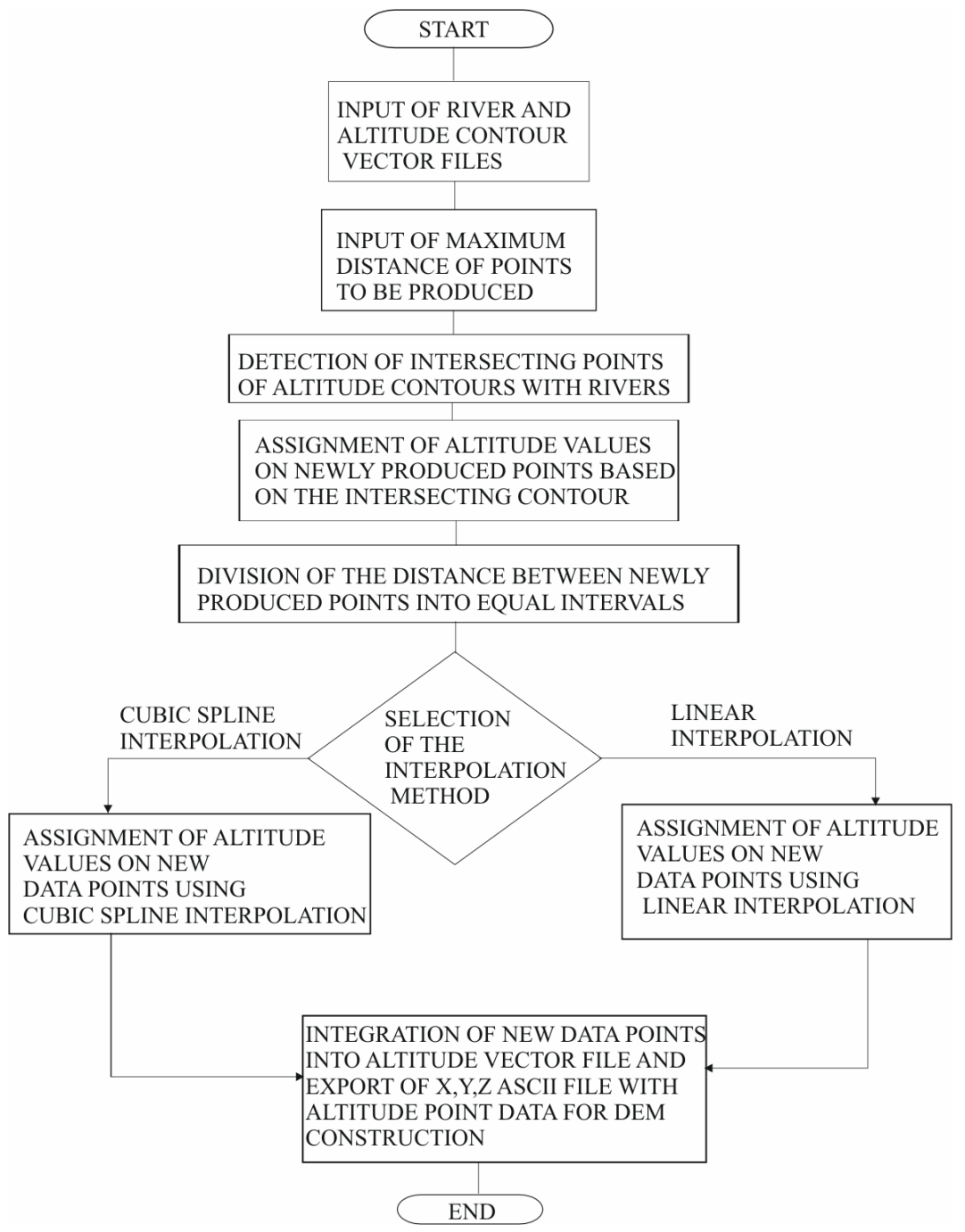

Figure 6. Flow chart of the developed software.

the study basin. All computations were performed using the GIS software MapInfo Professional ver. 9 and its raster tool Vertical Mapper ver. 3.1.

The usefulness and accuracy of LAN tool are demon- strated in two sub areas of the study region, i.e., one sub basin in the northern mountainous part which will be referred hereafter as TA1 (Test Area 1) and one in the southern lowland area, which will be referred as TA2 
(Test Area 2) (Figure 1). DEMs were constructed using the kriging interpolation method with and without the use of LAN tool and their accuracy was checked using various tests.

Kriging is based on the assumption that for a given point data set those that are close to each other are correlated whereas those at a further distance are statistically independent [23]. Its basic idea is equivalent to inverse distance weighted interpolation but instead of using weights based on an arbitrary function of distance in order to compute an interpolated point, the weights used in kriging are based on the model variogram. The model variogram is derived after constructing the experimental variogram from the point data set to be interpolated, like the one presented in Figure 7.

The experimental variogram is calculated by determining the variance of each data point in the data set with respect to all other data points and by plotting the variances (or semivariances) versus distance between points. The model variogram is then defined as a simple mathematical function that best fits the experimental variogram. As it can be seen on Figure 7, for small separating distances the variance of the variable to be interpolated is small whereas after a certain distance the variance becomes random. The model variogram is used to compute the weights used in kriging in order to evaluate an interpolated value $\mathrm{F}$ of the variable $\mathrm{f}$ based on the following equation:

$$
\mathrm{F}(\mathrm{x}, \mathrm{y})=\sum_{\mathrm{i}=1}^{\mathrm{n}} \mathrm{w}_{\mathrm{i}} \mathrm{f}_{\mathrm{i}}
$$

where $n$ in the number of points in the set, $f_{i}$ are the values of those points and $\mathrm{w}_{\mathrm{i}}$ are the weights assigned to each data point. In that way, if a new interpolated value $P$ it to be calculated from three neighboring points P1, P2, P3 then $\mathrm{w}_{1}, \mathrm{w}_{2}$ and $\mathrm{w}_{3}$ have to be determined solving a system of 3 equations based on the values of the model variogram evaluated at a distance equal to the distance between points $\mathrm{i}$ and $\mathrm{j}$.

There are various types of kriging. The one described above is known as ordinary kriging. Universal kriging is the kriging interpolation methodology that assumes data stationarity, i.e. the average value of the point data remains the same everywhere. Carter and Shankar [24], supported the use of kriging, stating several advantages of this approach: 1) predictions are based on the variogram; 2) the kriging system is constructed so as to minimize the variance of prediction errors while ensuring unbiasedness and 3) the error variance provides an indication of the uncertainty associated with each prediction. In every case, however, the LAN tool may well be used irrespective of the selected interpolation technique as it does not interfere with it, but enhances the altitude point data density in certain locations.

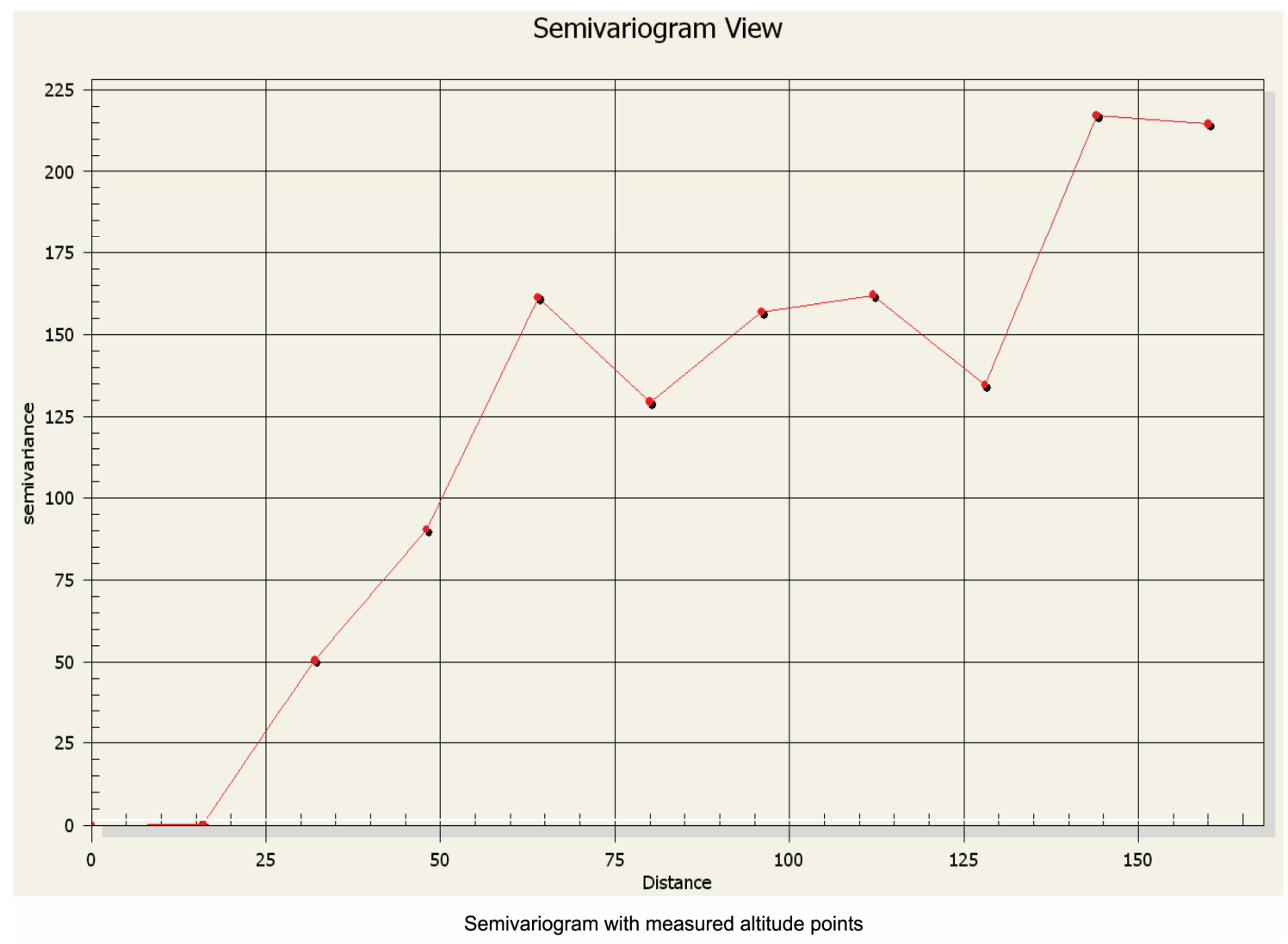




\section{Semivariogram View}

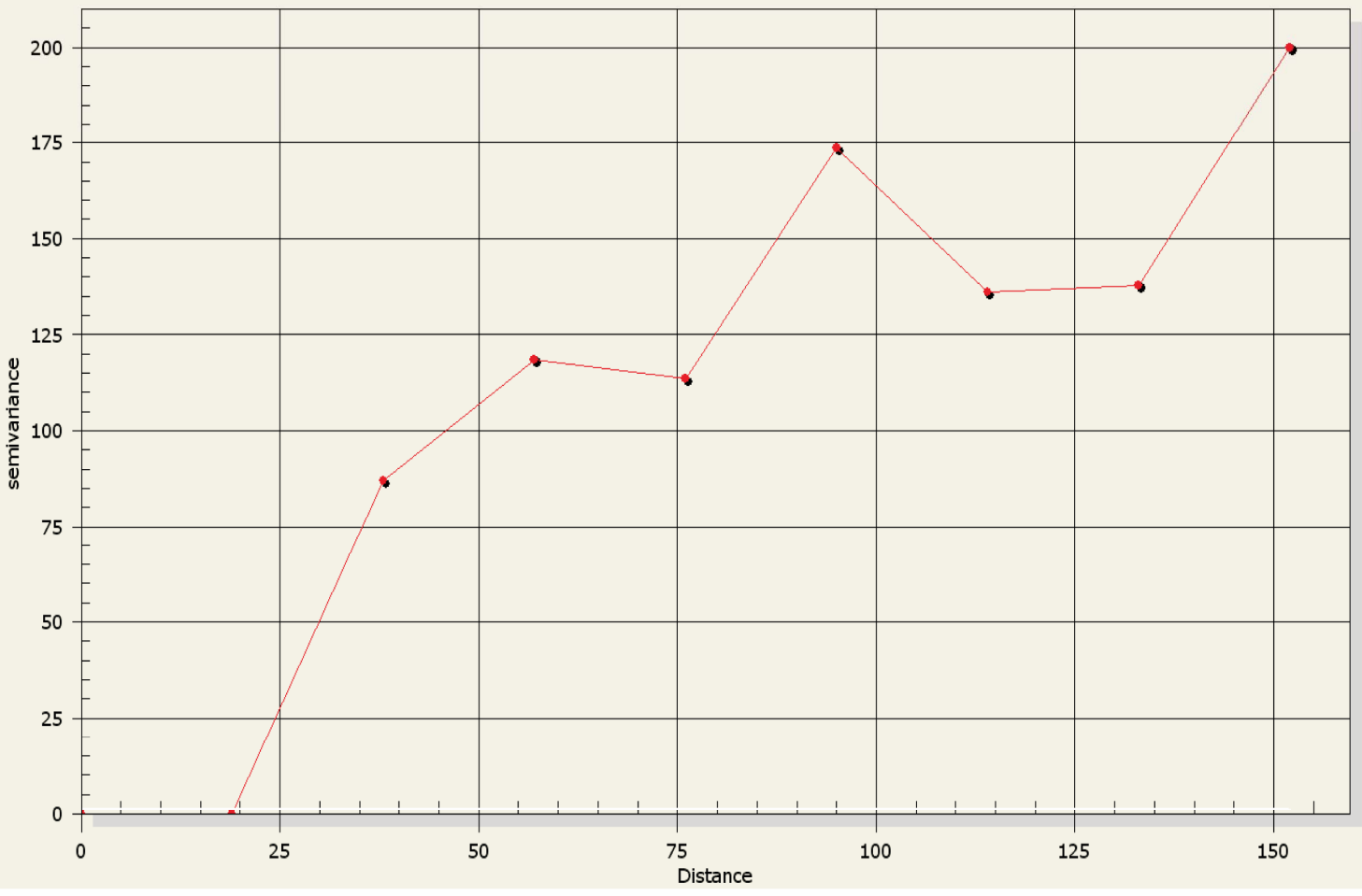

Semivariogram without the use of LAN tool

Semivariogram View

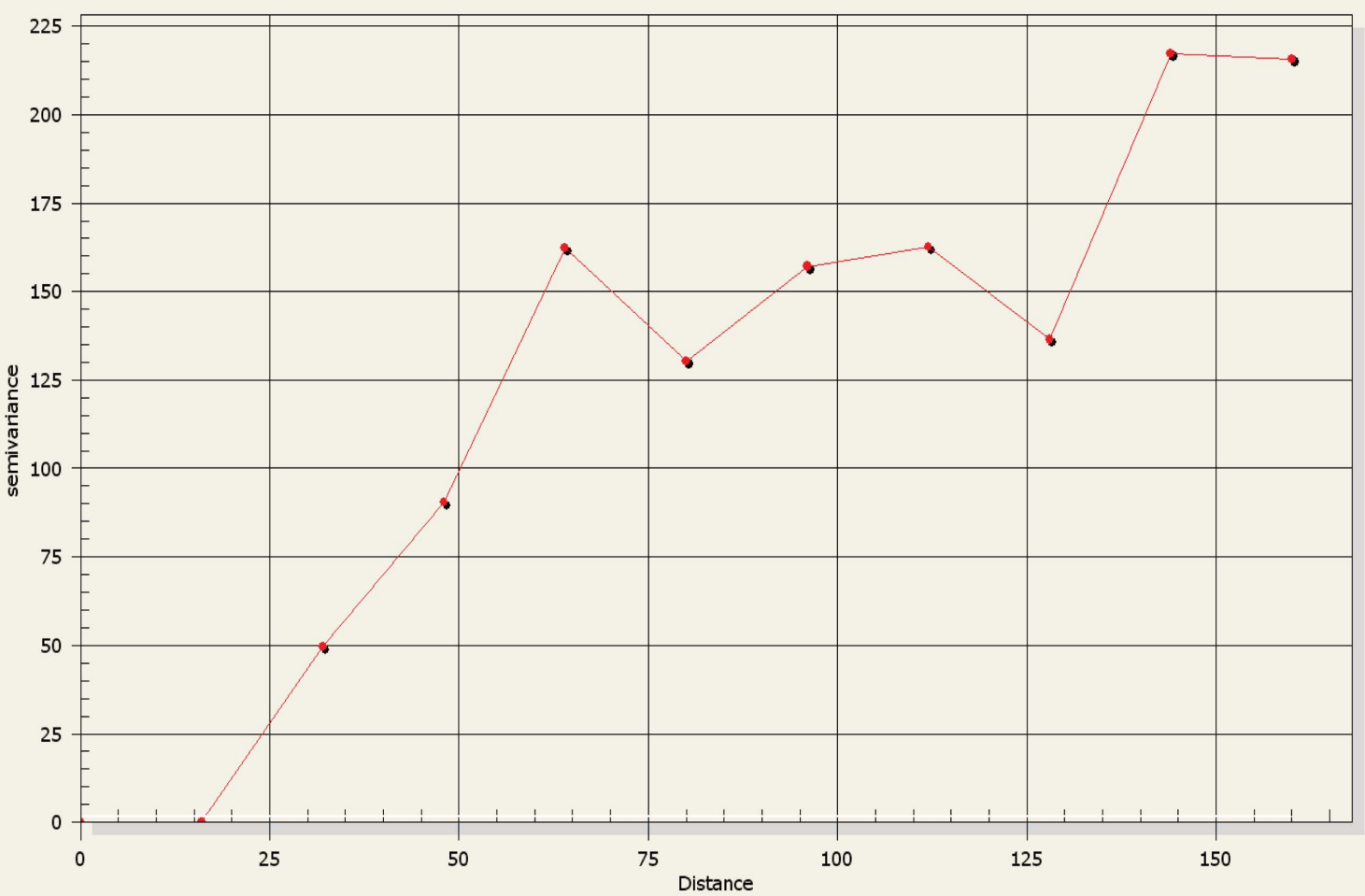

Semivariogram with the use of LAN tool

Figure 7. Comparison of semi variograms produced with and without the use of LAN tool, to the semi variogram with measured altitude data. 


\section{Results and Discussion}

\subsection{Application to TA1}

Figure 8 shows the altitude contours and the drainage network of TA1. In order to test the efficiency of the proposed methodology, DEM construction in TA1 was achieved with and without the use of LAN tool. The kriging interpolation technique was used in either case, as mentioned previously. The acquired results were compared to measured values of altitude performed using a
Trimble GPS Total Station R4.

Two independent tests were then performed; the first one compares the semi variograms produced with 50 measured altitude points, to those produced with the data points before and after the use of LAN tool in a small portion of TA1 highlighted as a red rectangle on Figure 8. In each case the lag distance used was the mean distance between data points. Figure 7 shows the semi variograms produced using only measured altitude points and those produced with and without the use of LAN tool.

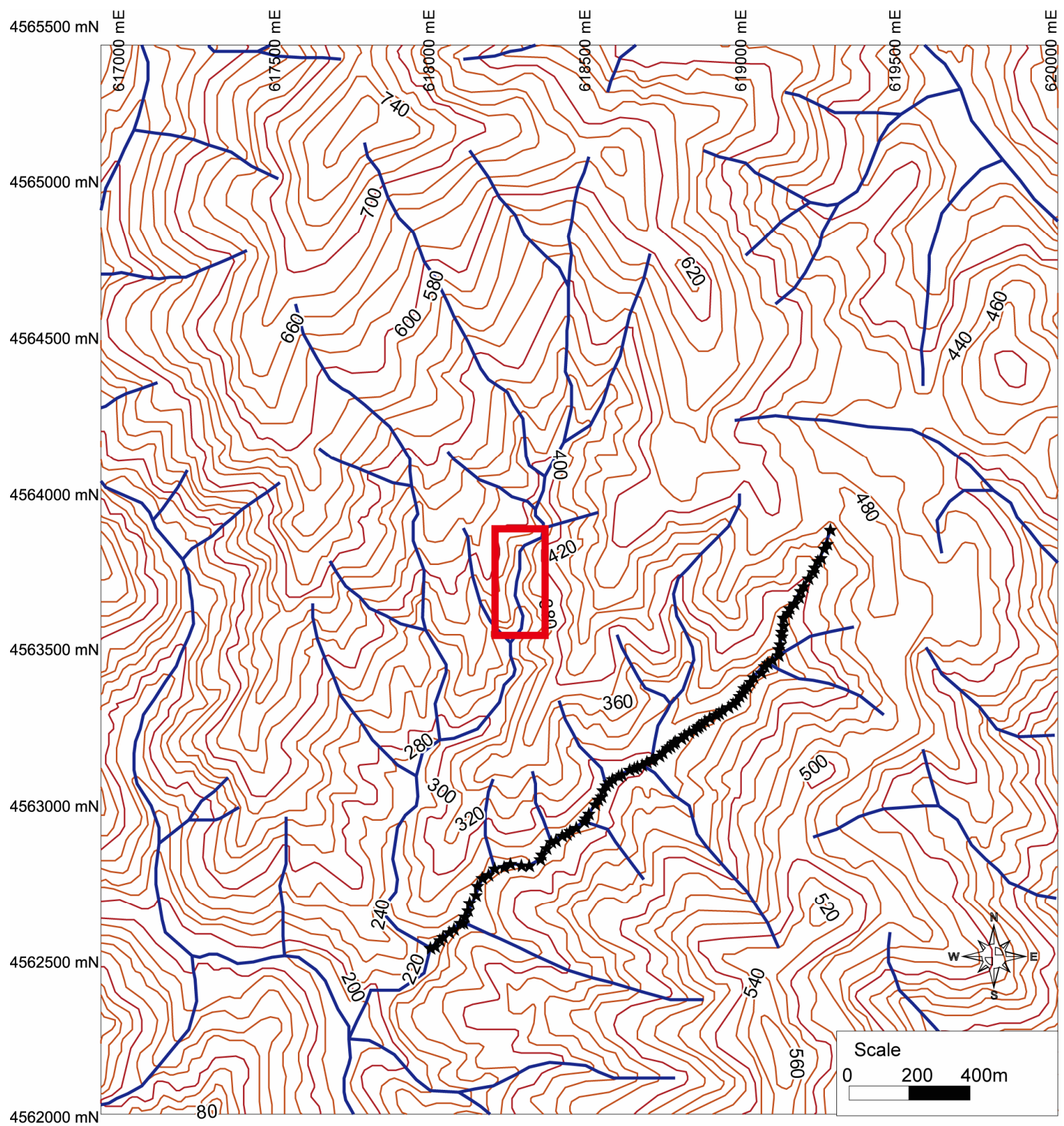

Figure 8. Map of TA1. Red rectangle highlights the area where semi variograms with and without the use of LAN tool, were compared to the semi variogram with measured data. Black spots indicate locations where altitude measurements on a main river branch were conducted. 
It can be seen that all three semi variograms present the same trend but the semi variograms of the measured points and that using points produced with LAN tool are almost identical.

The second test compares the altitude values produced with and without the application of LAN tool to measured altitude values on 100 randomly sampled data points located on one of the main branches of the drainage network of TA1 shown as black points on Figure 8. Figure 9(a) shows the river profiles produced with the measured altitude points and with and without the use of LAN tool. As it can be seen the profile produced using LAN tool is much closer to the measured one.
The mean absolute error (MAE) was calculated for the two profiles produced with and without the use of LAN tool, based on the following formula:

$$
\mathrm{MAE}=\frac{1}{\mathrm{~N}} \sum_{\mathrm{t}=1}^{\mathrm{N}}\left|\mathrm{Z}_{\mathrm{t}}-\hat{\mathrm{Z}}_{\mathrm{t}}\right|
$$

$\mathrm{Z}_{\mathrm{t}}$ being the interpolated altitude values, $\hat{\mathrm{Z}}_{\mathrm{t}}$ the measured altitude values and $\mathrm{N}$ the number of points, which in our case is 100 .

The MAE for the profiles produced with and without the use of LAN tool is $0.58 \mathrm{~m}$ and $2.39 \mathrm{~m}$ respectively.

Figures 9(b) and (c) present the DEMs produced without and with the use of LAN tool, respectively. From a

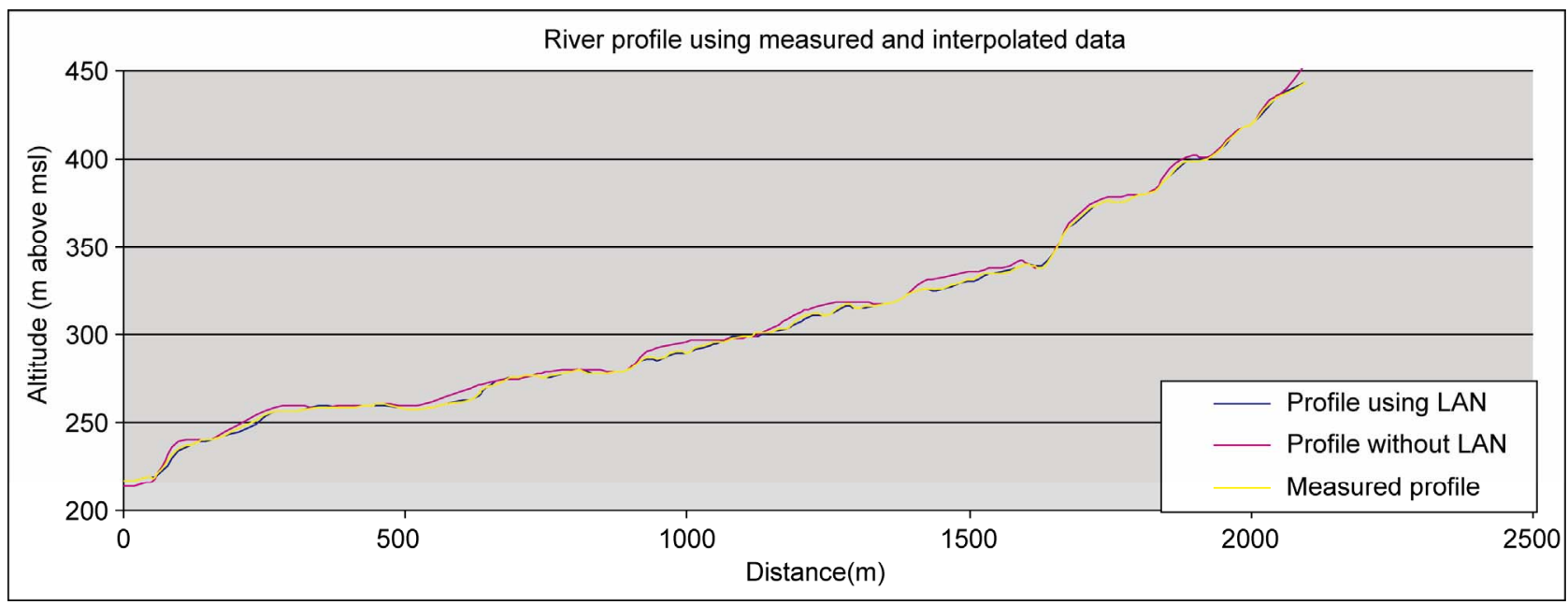

(a)

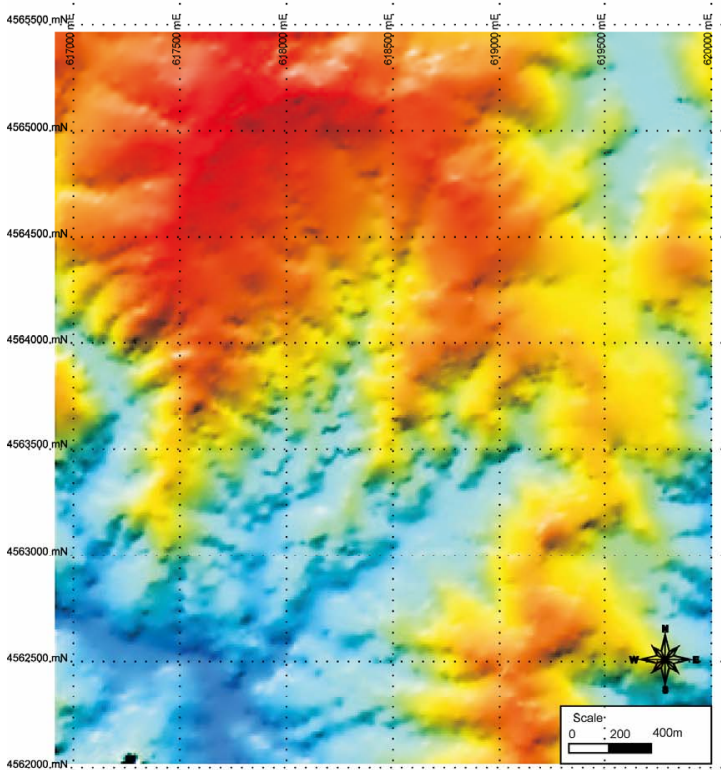

DEM produced without the use of LAN tool

(b)

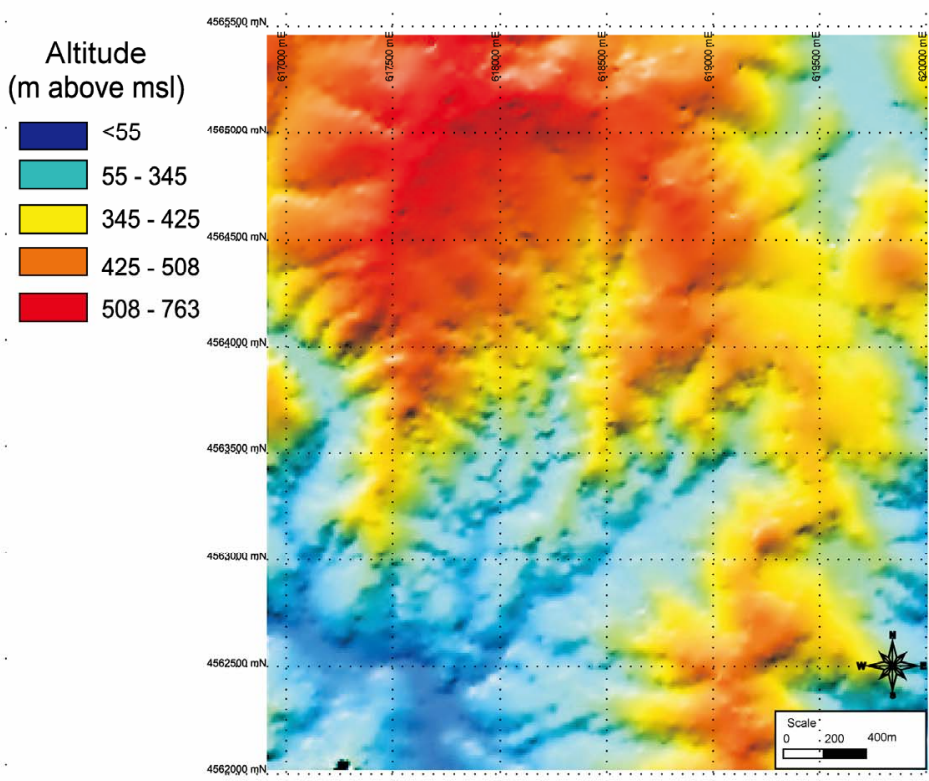

DEM produced with the use of LAN tool

(c)

Figure 9. Cross sectional plot of a river branch produced with and without the use of LAN tool and with measured altitude values. 
first point of view the DEMs produced using either method are very similar, but based on the comparison to the measured values, the LAN tool improved the produced DEM.

\subsection{Application to TA2}

In contrast to TA1, which is almost unaffected by human intervention, TA2 has undergone changes of the natural route of the drainage network, changing the main course of Vosvozis river and constructing irrigation and drainage channels. Additionally, Ismarida lake which is an important ecosystem, has decreased seriously in the last decade due to excess pumping. Thus, the topography of the area is also altered, which is not represented in the conventional maps that cannot be updated continuously. The main problem that arose is that when the DEM of TA2 was constructed, using topographic data from those conventional maps, the drainage network that was delineated using hydrologic models did not correspond to the existing network. Moreover, in plain areas, even in cases where no major human interventions have taken place, altitude contours are sparse, thus even the small errors associated with the interpolation technique may result in depressions that hinder flow or a drainage pattern which deviates considerably from the existing one.

In those cases, the use of LAN tool proves to be quite useful for DEM correction. As LAN tool requires the river network to be provided, an ASTER image of the study area acquired in August 2009 was used for the delineation of the river network (Figure 10).

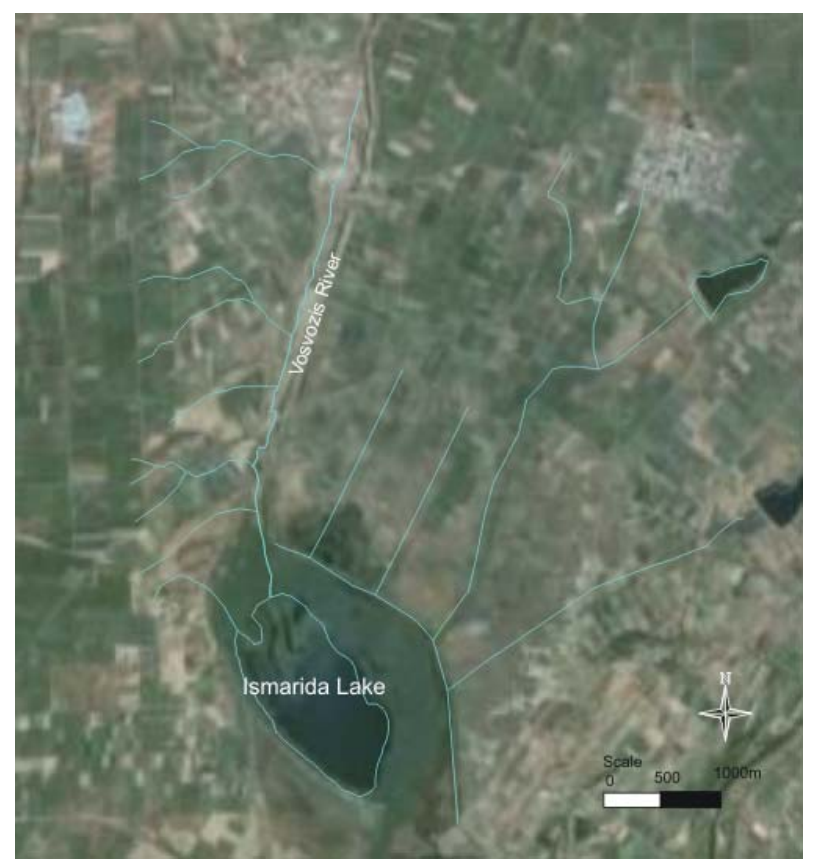

Figure 10. Aster image acquired on August 2009, showing the river network of TA2.
Topographic data were digitized using conventional topographic maps of the Hellenic Military Geographical Service of scale 1:5000. Kriging interpolation was used to create a DEM, with and without the use of LAN tool. The produced DEMs were introduced to one of the most popular hydrologic models, i.e. Soil and Water Assessment Tool (SWAT) [25], in order to delineate automatically the drainage network. The results were compared to the existing drainage network. Figure $\mathbf{1 0}$ shows the drainage network delineated from the ASTER image. Figure 11(a) shows the drainage network produced by automatic delineation using the DEM without the use of LAN tool (Figure 11(b)).

Figure 12(a) shows the drainage network produced by automatic delineation using the DEM with the use of LAN tool shown on Figure 12(b). Comparison of the produced results shows that the river network delineated based on the DEM with the use of LAN tool is much closer to the real one. Additionally, one can easily distinguish the artificial irrigation pond shown on the north east of Figure 12(b), which is incorporated in the DEM using LAN tool. Thus LAN tool proved to be quite effective in TA2.

At this point the findings of the research conducted by Chaplot et al. [12] should be mentioned. They found that irrespective of the surface area, landscape morphology and sampling density, few differences existed between the employed interpolation techniques if the sampling density was high. At lower sampling densities, in contrast, the performance of the techniques tended to vary. Within this context the usefulness of LAN tool is unambiguous at it increases sampling density in specified locations where most of the DEM inaccuracies tend to exist. Besides the fact that kriging was used for demonstration purposes, the same improved results on the DEM are expected with all other interpolation techniques, as LAN tool does not alter the interpolation itself, but it provides a higher point data density in areas of interest.

\section{Conclusions}

This paper demonstrates the use of a newly developed GIS tool, namely LAN tool, which helps in the improvement of DEMs. The main idea is to increase point density data in areas where conventional interpolation produces problematic results, such as plain areas or river beds. For this purpose information provided by the delineation of linear features, such as river network is used. Two applications of LAN tool were presented, one in a mountainous area and the other in a lowland area. Independent tests were performed in order to prove the effectiveness of LAN tool. In the first case, i.e. TA1, the tests were based on field altitude measurements. Results showed that a considerable improvement in DEM was 


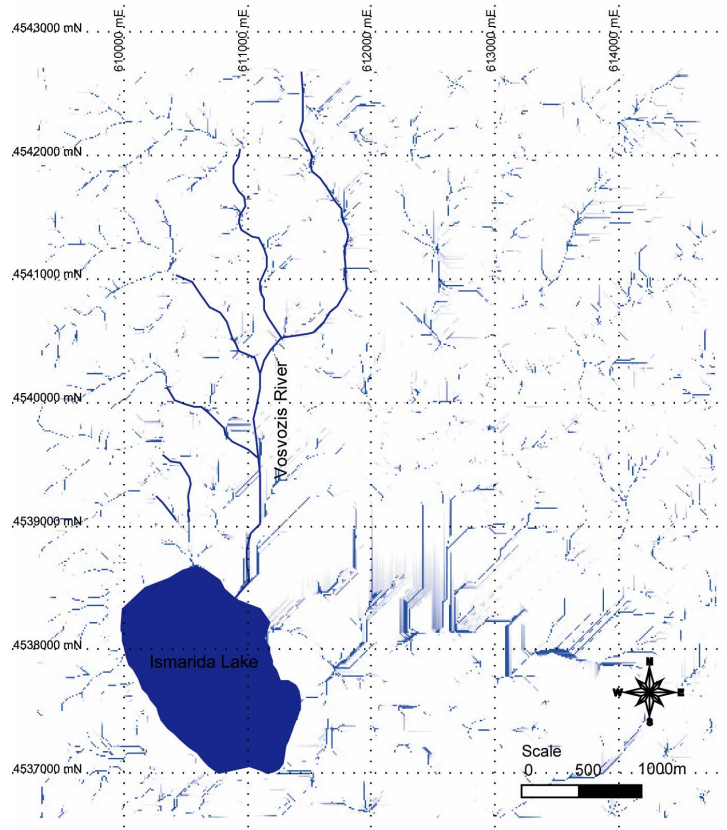

(a)

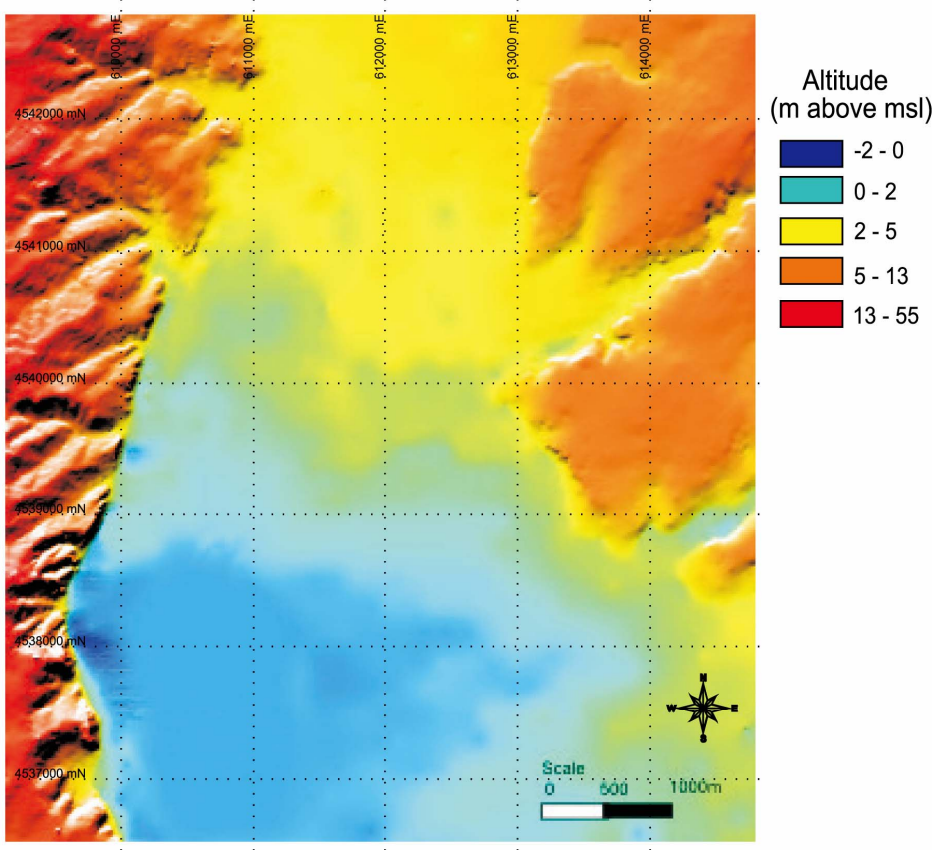

(b)

Figure 11. (a) River network produced with automatic delineation using SWAT model using DEM without the use of LAN tool; (b) DEM produced without the use of LAN tool.

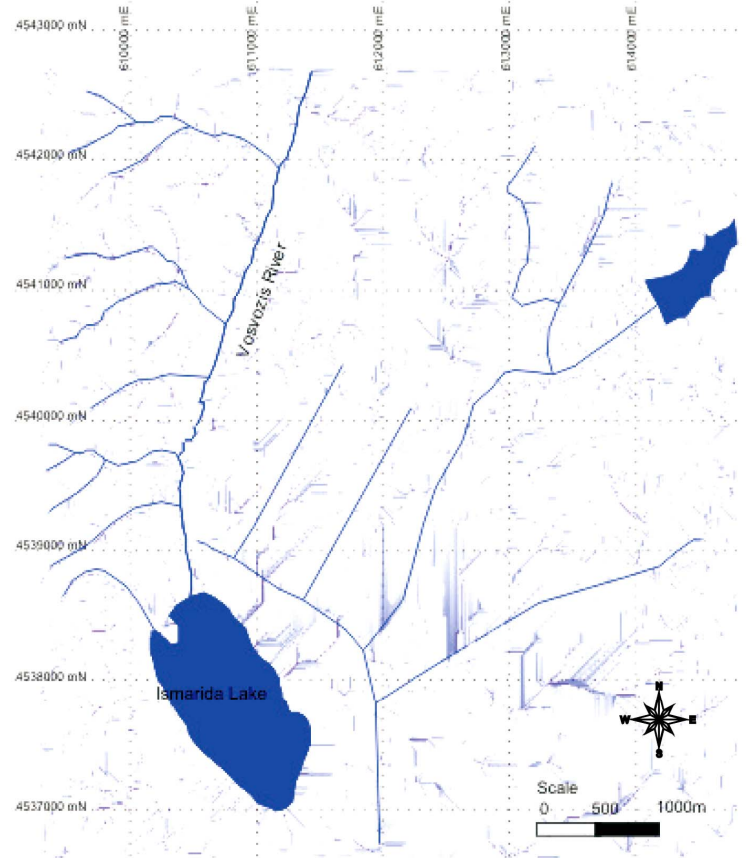

(a)

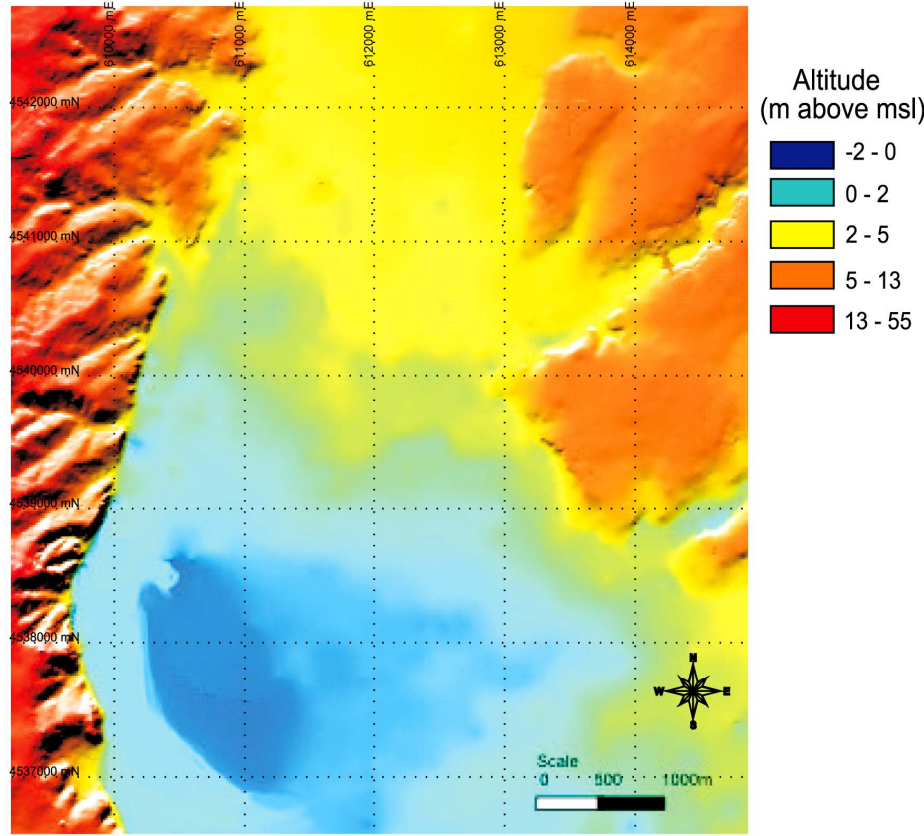

(b)

Figure 12. River network produced with automatic delineation using SWAT model using DEM with the use of LAN tool; (b) DEM produced with the use of LAN tool.

achieved, as indicated by the minimization of MAE.

In the second case, i.e. TA2, where serious interventions on the drainage network had taken place, the improvement using LAN tool was obvious, as the produced
DEM represented accurately the current pattern of the drainage network.

As this application is merely focused on hydrologic surveys, the drainage network has been used as the line 
attribute network. Analogous applications may well be developed using LAN tool with other line attribute networks, like roads or any other linear feature.

\section{Acknowledgements}

The field measurements conducted in the present work were part of the project: "Water resources management in Eastern Macedonia and Thrace” funded by the Technical Chamber of Greece (project code: 2237 Democritus University of Thrace).

\section{REFERENCES}

[1] C. Legleiter and P. Kyriakidis, "Spatial Prediction of River Channel Topography by Kriging,” Earth Surface Processes and Landforms, Vol. 33, No. 6, 2008, pp.841-867. doi:10.1002/esp.1579

[2] V. Chaplot, "Impact of DEM Mesh Size and Soil Map Scale on SWAT Runoff, Sediment, and $\mathrm{NO}_{3}-\mathrm{N}$ Loads Predictions," Journal of Hydrology, Vol. 312, No. 1-4, 2005, pp. 207-222.

[3] L. Kalin, R. S. Govindarajua and M. M. Hantush, "Effect of Geomorphologic Resolution on Modeling of Runoff Hydrograph and Sedimentograph over Small Watersheds," Journal of Hydrology, Vol. 276, No. 1-4, 2003, pp. 89111. doi:10.1016/S0022-1694(03)00072-6

[4] A. R. Darnell, A. A. Lovett, J. Barclay and R. A. Herd, “An Application Driven Approach to Terrain Model Construction," International Journal of Geographical Information Science, Vol. 24, No. 8, 2010, pp. 1171-1191. doi:10.1080/13658810903318889

[5] J. Kiesel, N. Fohrer, B. Schmalz and M. J. White, "Incorporating Landscape Depressions and Tile Drainages of a Northern German Lowland Catchment into a Semi-Distributed Model,” Hydrological Processes, Vol. 24, No. 11, 2010, pp. 1472-1486. doi:10.1002/hyp.7607

[6] H. Achour, N. Rebai, J. Van Den Driessche and S. Bouaziz, "Modelling Uncertainty of Stream Networks Derived from Elevation Data Using Two Free Softwares: R and SAGA,” Journal of Geographic Information System, Vol. 4, No. 2, 2012, pp. 153-160. doi:10.4236/jgis.2012.42020

[7] D. Weber and E. Englund, "Evaluation and Comparison of Spatial Interpolators,” Mathematical Geology, Vol. 24, No. 4, 1992, pp. 381-391. doi:10.1007/BF00891270

[8] D. Weber and E. Englund, "Evaluation and Comparison of Spatial Interpolators II,” Mathematical Geology, Vol. 26, No. 5, 1994, pp. 589-603. doi:10.1007/BF02089243

[9] A. Carrara, G. Bitelli and R. Carla, "Comparison of Techniques for Generating Digital Terrain Models from Contour Lines," International Journal of Geographical Information Science, Vol. 11, No. 5, 1997, pp. 451-473. doi:10.1080/136588197242257

[10] S. M. Robeson, "Spherical Methods for Spatial Interpolation: Review and Evaluation,” Cartography and Geographic Information Systems, Vol. 24, No. 1, 1997, pp. 3-20. doi:10.1559/152304097782438746

[11] F. J. Aguilar, F. Agüera, M. A. Aguilar and F. Carvajal,
"Effects of Terrain Morphology, Sampling Density, and Interpolation Methods on Grid DEM Accuracy,” Photogrammetric Engineering and Remote Sensing, Vol. 71, No. 7, 2005, pp. 805-816.

[12] V. Chaplot, F. Darboux, H. Bourennane, S. Leguédois, N. Silvera and K. Phachomphon, "Accuracy of Interpolation Techniques for the Derivation of Digital Elevation Models in Relation to Landform Types and Data Density," Geomorphology, Vol. 77, No. 1-2, 2006, pp. 126-141. doi:10.1016/j.geomorph.2005.12.010

[13] S. J. Buckley and H. L. Mitchell, "Integration, Validation and Point Spacing Optimization of Digital Elevation Models," The Photogrammetric Record, Vol. 19, No. 108, 2004, pp. 277-295. doi:10.1111/j.0031-868X.2004.00287.x

[14] M. Karkee, B. L. Steward and S. A. Aziz, "Improving Quality of Public Domain Digital Elevation Models through Data Fusion,” Biosystems Engineering, Vol. 101, No. 3, 2008, pp. 293 -305. doi:10.1016/j.biosystemseng.2008.09.010

[15] W. Z. Shi and Y. Tian, “A Hybrid Interpolation Method for the Refinement of a Regular Grid Digital Elevation Model," International Journal of Geographical Information Science, Vol. 20, No. 1, 2006, pp. 53-67. doi:10.1080/13658810500286943

[16] O. Bonin and D. Rousseaux, "Digital Terrain Model Computation from Contour Lines: How to Derive Quality Information from Artifact Analysis," GeoInformatica, Vol. 9, No. 10, 2005, pp. 253-268. doi:10.1007/s10707-005-1284-2

[17] Y. Chen, J. P. Wilson, Q. Zhu and Q. Zhou, “Comparison of Drainage-Constrained Methods for DEM Generalization," Computers and Geosciences, Vol. 48, 2012, pp. 4149. doi:10.1016/j.cageo.2012.05.002

[18] W. Saunders, "Preparation of DEMs for Use in Environmental Modelling Analysis,” In: D. Maidment and D. Djokic, Eds., Hydrologic and Hydraulic Modelling Support with Geographic Information Systems, Environmental Systems Research Institute Inc., Redlands, 2000, pp. 29-51.

[19] J. N. Callow, K. P. Van Niel and G. S. Boggs, "How Does Modifying a DEM to Reflect Known Hydrology Affect Subsequent Terrain Analysis?” Journal of Hydrology, Vol. 332, No. 1-2, 2007, pp. 30-39. doi:10.1016/j.jhydrol.2006.06.020

[20] M. F. Hutchinson, "A New Procedure for Gridding Elevation and Stream Line Data with Automatic Removal of Spurious Pits,” Journal of Hydrology, Vol. 106, No. 3-4, 1989, pp. 211-232. doi:10.1016/0022-1694(89)90073-5

[21] Q. Zhou and Y. Chen, "Generalization of DEM for Terrain Analysis Using a Compound Method," ISPRS Journal of Photogrammetry and Remote Sensing, Vol. 66, No. 1, 2011, pp. 38-45. doi:10.1016/j.isprsjprs.2010.08.005

[22] D. Souvaine, "Line Segment Intersection Using a Sweep Line Algorithm,” Tufts University, 2005.

http://www.cs.tufts.edu/comp/163/notes05/seg_intersectio n_handout.pdf

[23] J. C. Davis, "Statistics and Data Analysis in Geology," 2nd Edition, John Wiley and Sons, New York, 1986. 
[24] G. S. Carter and U. Shankar, "Creating Rectangular Bathymetry Grids for Environmental Numerical Modelling of Gravel-Bed Rivers,” Applied Mathematical Modelling, Vol. 21, No. 11, 1997, pp. 699-708.

doi:10.1016/S0307-904X(97)00094-2
[25] M. Winchell, R. Srinivasan, M. Di Luzio and J. Arnold, “ARCSWAT 2.0 Interface for SWAT 2005, User's Guide," Blackland Research Center, Texas Agricultural Research Station and USDA Agricultural Research Service, 2008. 